\title{
CIGS Nanoparticles Observed in TEM Low Dose Condition. Atomic Resolution and Beam Effects.
}

\author{
I. Santana-García ${ }^{1}$, C. Kisielowski ${ }^{2}$, P. Specht ${ }^{3}$ and H. A. Calderon ${ }^{1}$. \\ 1. Depto. Física, ESFM-IPN, Zacatenco D.F. Mexico. \\ 2. JCAP and NCEM, LBNL, Berkeley, CA 94720, U.S.A. \\ 3. Dept. Mats. Sci. Eng., UCB, Berkeley, CA 94720.
}

CIGS ( $\left.\mathrm{CuIn}_{\mathrm{x}} \mathrm{Ga}_{(1-\mathrm{x})} \mathrm{Se}_{2}\right)$ is a semiconducting photovoltaic material with the chalcopyrite crystal structure and a band gap varying with $\mathrm{x}$ from approximately $1.0 \mathrm{eV}$ (CIS) to around $1.7 \mathrm{eV}$ (CGS). These nanoparticles can be used to transform solar energy into electricity and are attractive for solar cells. Since their band gap is susceptible to be modified as a function of size, it becomes interesting to synthesize and characterize nanoparticles for solar energy harvesting with different band gaps. Typically CIGS nanoparticles are developed in colloids by a variety of procedures. In this investigation both colloid formation and reactive mechanical milling methods are used for synthesis. Reactive mechanical milling is a simple procedure where a chemical reduction is induced during milling at room temperature. This gives rise to a fine nanoparticle distribution if coagulation is restrained e.g. by adding a dispersing media. GIGS nanoparticles in the present report have all been produced by reactive milling (with $\mathrm{x}=$ 0.3 ), starting with chlorides and chemically reducing them with $\mathrm{Na}$ in an excess of $\mathrm{NaCl}$ to promote dispersion.

Figure 1 shows three $\mathrm{X}$ ray diffraction patterns, all of them with the expected peaks for the chalcopyrite structure and as a function of milling time. The peaks angular position varies with milling time. Interestingly relatively short milling times produce rather small particles that slightly coarsen as milling time proceeds. There are also small changes in lattice parameter most like due to chemical homogenization taking place for the different milling times.

Low dose imaging in TEM has been used to investigate the synthesized nanoparticles. This is most likely the only possible manner to image them. CIGS nanoparticles are very sensitive to the electron beam and it has been possible to document subtle changes that take place under rather low dosages in short times. Figures 2-5 show phase images of nanoparticles corresponding to 10 and $3 \mathrm{~h}$ of milling time after exit wave reconstruction (MacTempass ${ }^{\circledR}$ ). There is a mixture of particle sizes with some of them being relatively large and around 5-7 nm (Figs. 2a,b) and others smaller and close to $2 \mathrm{~nm}$ (Fig. 3a). All of them show projections of the chalcopyrite structure and different column intensities denoting different atomic species. Image simulation has been carried out in order to establish the most likely chemical composition in the atomic columns. As for the beam sensitivity, Fig. 3 shows and example with two focal series (and phase images) taken at a dose rate of $25 \mathrm{e}^{-} / \AA^{2} \mathrm{~s}$ (Fig. 3a) and after $2 \mathrm{~min}$ at a slightly higher dose $\left(100 \mathrm{e}^{-} / \AA^{2} \mathrm{~s}\right)$. The phase image clearly varies as the beam exposure increases even at such low dose rates. Figure 4 shows examples of nanoparticles (phase images) after $3 \mathrm{~h}$ of milling. Smaller particles are found but not very different in size as compared to $10 \mathrm{~h}$ of milling. Fig. 5 shows the dynamics of transformation of an isolated nanoparticle as it is exposed to a dose rate of $10 \mathrm{e}^{-} / \AA^{2} \mathrm{~s}$ and a focal series is taken (about $1 \mathrm{~min}$, Fig. 5a), then the dose rate is increased to $40 \mathrm{e}^{-} / \AA^{2} \mathrm{~s}$ (Fig. 5b) and finally to $200 \mathrm{e}^{-} / \AA^{2} \mathrm{~s}$ (Fig. 5c). After an exposure time of around $1 \mathrm{~min}$ to this higher dose rate, the particle looses the characteristics observed at the lowest dose rate $\left(10 \mathrm{e}^{-} / \AA^{2} \mathrm{~s}\right)$. Clearly there is a very 
high sensitivity of the nanopartices to the electron beam, however by decreasing the dose rate it is possible to achieve the desired atomic level characterization.

\section{References:}

[1] HAC whishes to acknowledge support from CONACYT and COFAA. SIP-IPN.

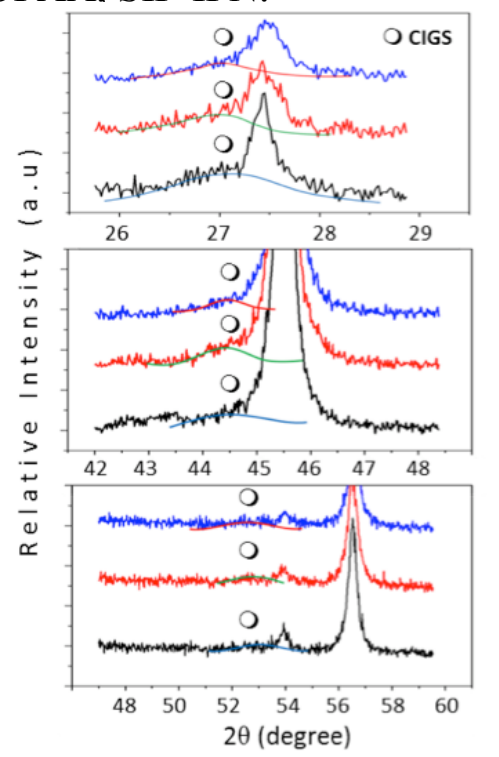

Figure 1. X-Ray diffraction patterns showing chalcopyrite type reflections after (a) 3, (b) 7 and (c) $10 \mathrm{~h}$ of milling.
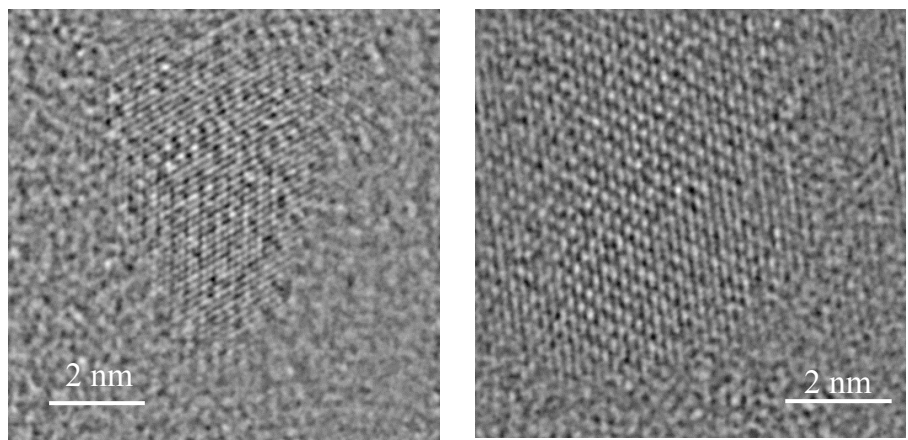

Fig. 2. Phase images of CIGS nanoparticles after $10 \mathrm{~h}$ of milling. An exit wave reconstruction procedure has been performed with a focal series of 40 images.
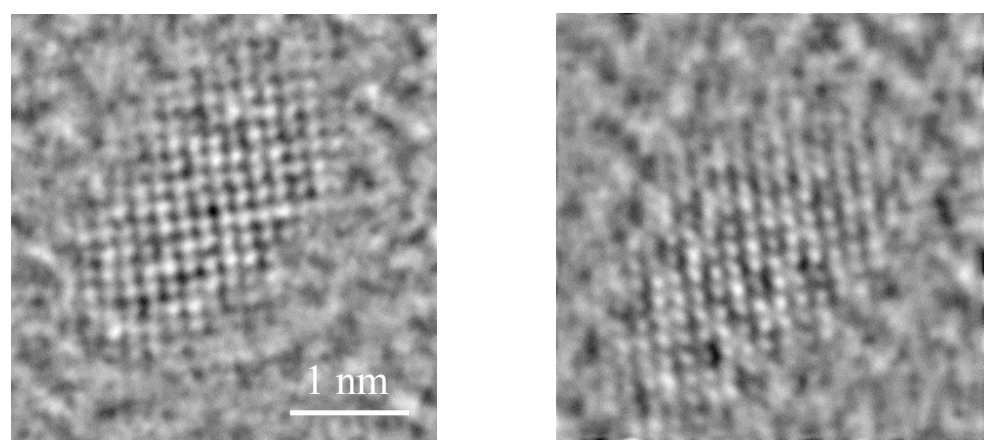

Fig. 3. Phase images of a CIGS nanoparticles. (a) after 1 min under $25 \mathrm{e}^{-/} /$As , followed by (b) 2 min at $100 \mathrm{e}^{-} / \AA^{2} \mathrm{~s}$.
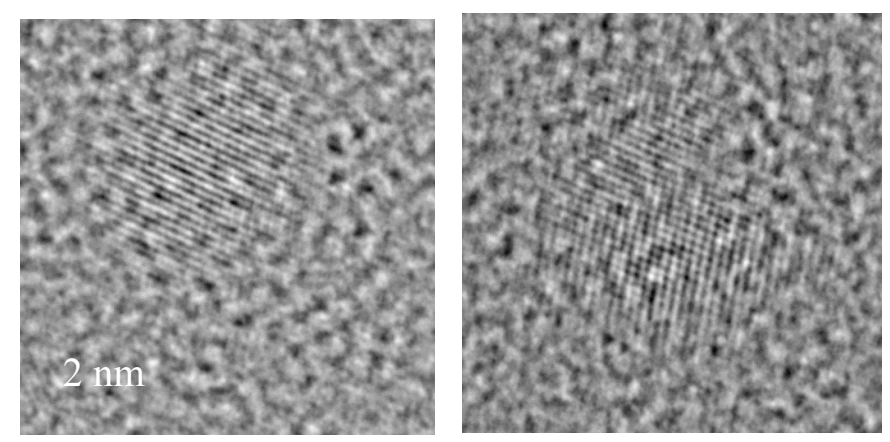

Figure 4. Phase images of CIGS nanoparticles after $3 \mathrm{~h}$ of reactive milling. Shape are rarely spherical but crystalline structure is as expected. Dose rate $65 \mathrm{e}^{-} / \AA^{2} \mathrm{~s}$.
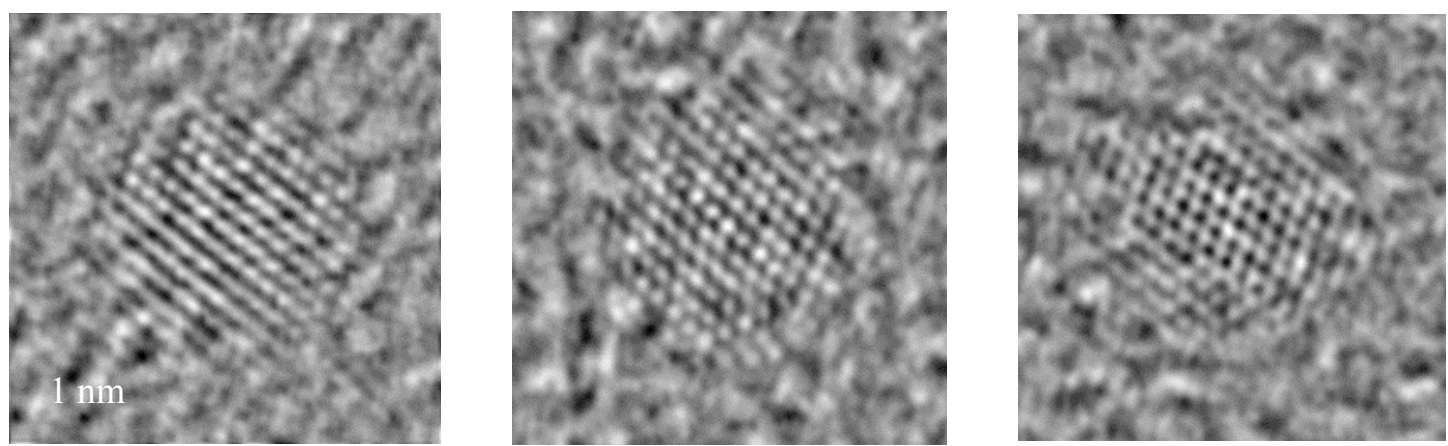

Fig. 5. CIGS nanoparticle sensitivity to beam exposure. Dose rate of (a) $10 \mathrm{e}^{-} / \AA^{2} \mathrm{~s}$, (b) $40 \mathrm{e}^{-} / \AA^{2} \mathrm{~s}$, (c) $200 \mathrm{e}^{-} / \AA^{2} \mathrm{~s}$ 